\title{
Longitudinal observation of the retinal nerve fibre layer in glaucoma patients treated with brimonidine combined with timolol or timolol alone
}

\author{
Adrian Smedowski ${ }^{1,2}$, Dorota Tarnawska ${ }^{1,3}$, Kai Kaarniranta, ${ }^{4,5}$, Edward Wylegala ${ }^{1}$ \\ ${ }^{1}$ Department of Ophthalmology, School of Medicine with the Division of Dentistry in Zabrze, Medical University of Silesia, Katowice, Poland \\ ${ }^{2}$ Chair and Department of Physiology, School of Medicine in Katowice, Medical University of Silesia, Katowice, Poland \\ ${ }^{3}$ Department of Biophysics and Molecular Physics, Institute of Physics, University of Silesia, Katowice, Poland \\ ${ }^{4}$ Department of Ophthalmology, University of Eastern Finland, Kuopio, Finland \\ ${ }^{5}$ Department of Ophthalmology, Kuopio University Hospital, Kuopio, Finland
}

\begin{abstract}
INTRODUCTION. The aim of the study was to evaluate the retinal nerve fibre layer (RNFL) thickness loss in primary open-angle glaucoma (POAG) patients treated topically with anti-glaucoma drops containing brimonidine and timolol combination or solely timolol.

MATERIALS AND METHODS. Retrospective case series study of patients with POAG diagnosis followed up for a five-year period. Inclusion criteria were fulfilled by a group of 98 patients consisting of 53 combination and 45 monotherapy treatments. Intraocular pressure (IOP) at the level of $21 \mathrm{~mm} \mathrm{Hg}$ or below for each measurement was observed in 52 patients, while incidences of pressure above $21 \mathrm{~mm} \mathrm{Hg}$ were measured in 46 patients. POAG diagnosis was based on standard optical coherence tomography, IOP, and visual field examinations.

RESULTS. Mean annual loss of RNFL thickness in the overall study group (if IOP levels are not taken into consideration) treated with timolol monotherapy was $1.8 \pm 1.5 \mu \mathrm{m}$, while in group treated with brimonidine + timolol combination therapy it was $1.7 \pm 1.5 \mu \mathrm{m}(\mathrm{p}>0.05)$. In selected groups of patients with incidents of pressure rises, the mean annual loss of retinal nerve fibre layer thickness was $1.8 \pm 1.6$ and $1.9 \pm 1.4 \mu \mathrm{m}$, respectively, for the monotherapy and combination therapy groups $(\mathrm{p}>0.05)$. In the group of patients with no reported IOL rises, mean annual loss of RNFL thickness was $1.8 \pm 0.9$ and $1.1 \pm 0.4 \mu \mathrm{m}$, respectively, for the monotherapy and combination therapy groups $(\mathrm{p}<0.01)$. No significant differences were observed for the visual field mean deviation.

CONCLUSIONS. POAG patients with low values of IOP might achieve slower progression of RNFL thinning on brimonidine combined with timolol therapy.
\end{abstract}

KEY WORDS: primary open angle glaucoma, brimonidine, retinal nerve fibre layer, glaucoma progression

Ophthalmol J 2017; Vol. 2, No. 1, 13-16

\section{INTRODUCTION}

According to the World Health Organization, glaucoma is the second most common cause of blindness worldwide [1]. A basic measurable pathogenic factor of glaucomatous injury to the optic nerve is increased intraocular pressure (IOP), which is associated with $70 \%$ of cases $[2,3]$.

Current glaucoma treatment focuses only on lowering the increased IOP; however, active research is taking place of mechanisms that evoke retinal 
ganglion cell (RGC) damage aiming to find a new neuroprotective target to prevent blindness [4]. Brimonidine, $\alpha_{2}$-adrenergic receptor agonist, has been documented to have neuroprotective potential under experimental conditions, while clinical trials do not unequivocally support this discovery [4-9].

We report a five-year retrospective analysis of retinal nerve fibre layer (RNFL) thickness, IOP, and visual field (VF) of primary open angle glaucoma (POAG) patients treated with either topical brimonidine/timolol combination therapy or solely with timolol.

\section{MATERIALS AND METHODS}

A five-year retrospective analysis of 1800 POAG patients was performed, from among of which we selected patients fulfilling the inclusion criteria: availability of annual ocular coherence tomography (OCT) data (TD-OCT Stratus; Carl Zeiss Meditec, Dublin, CA, USA) and VF (30-2 Humphrey test, Humphrey 740, Carl Zeiss Meditec, Dublin, CA, USA) for five years, at least three annual IOP measurements (Goldmann Applanatory Tonometer, GAT, Haag-Streit AG, Switzerland), and continuous five-year treatment with either a combination of topical brimonidine + timolol (Combigan, Allergan, Irvine, CA, USA) or solely with timolol (Oftensin $0.5 \%$, Polpharma, Warsaw, Poland). Based on the above criteria, 98 patients (69 females and 29 males, in the age range 38 to 89 years) were included in study group. All patients' mean five-year IOP was below the normative $21 \mathrm{~mm} \mathrm{Hg}$; however, we observed patients who tended to have single, short-lasting IOP elevations above $21 \mathrm{~mm} \mathrm{Hg}$. Patients were divided into the following groups: group BT ( $\mathrm{n}=53$ patients, 104 eyes $)$ - all patients treated with brimonidine + timolol combination therapy; group $\mathrm{T}(\mathrm{n}=45$ patients, 89 eyes $)$ - all patients treated with timolol monotherapy; group $\mathrm{BT}^{-}$ $(\mathrm{n}=32$ patients, 63 eyes $)$ - brimonidine + timolol combination therapy with no IOP increase above $21 \mathrm{~mm} \mathrm{Hg}$ during follow-up time; group $\mathrm{T}^{-}$ ( $\mathrm{n}=20$ patients, 40 eyes - timolol monotherapy with no IOP increase above of $21 \mathrm{~mm} \mathrm{Hg}$ during follow-up time; group $\mathrm{BT}^{+}(\mathrm{n}=21$ patients, 41 eyes $)$ - brimonidine/timolol combination therapy with IOP rise above $21 \mathrm{~mm} \mathrm{Hg}$ during follow-up time; and group $\mathrm{T}^{+}$(25 patients, 49 eyes) - timolol monotherapy with IOP rise above $21 \mathrm{~mm} \mathrm{Hg}$ during follow-up. Progression of glaucoma in all patients was apparent when examined with OCT (RNFL thin- ning) as well as with VF (MD defect). Treatment was constant for the entire five-year period. The normative IOP was defined as less than $21 \mathrm{~mm} \mathrm{Hg}$ and IOP elevation as above $21 \mathrm{~mm} \mathrm{Hg}$.

\section{RESULTS}

Mean five-year IOP values, as well as input RNFL thickness, were not significantly different between groups ( $p>0.05$, Mann Whitney U-test; Tab. 1). No statistically significant differences for the mean values of MD, mean final RNFL thickness, loss of RNFL thickness, or the annual rate of loss ( $p>0.05$, Mann Whitney U-test) were seen between groups BT and T (Tab. 1; Fig. 1 A-C). In these groups the presence of reported increases of IOP above $21 \mathrm{~mm} \mathrm{Hg}$ affected RNFL thickness $(\mathrm{p}<0.03$, Mann Whitney U-test). Therefore, overall patients' groups were divided into subgroups with or without reported single IOP rises.

\section{GROUPS WITH REPORTED IOP ELEVATIONS}

No statistical significance between the $\mathrm{BT}^{+}$and $\mathrm{T}^{+}$ groups was observed for mean values of the MD change, the mean final RNFL thickness, the loss of RNFL thickness, or the annual rate of loss ( $p>0.05$, Mann-Whitney U-test) (Tab. 1; Fig. 1 D-F).

\section{GROUPS WITH NO REPORTED IOP ELEVATIONS}

In contrast to the group with reported IOP increase, the group with no single IOP elevations above $21 \mathrm{~mm} \mathrm{Hg}$ (group $\mathrm{BT}^{-}$vs. group $\mathrm{T}^{-}$) showed statistically significant differences in the loss of RNFL thickness, the annual rate of RNFL loss $(\mathrm{p}<0.01$, Mann-Whitney U test), and the mean final RNFL thickness ( $p<0.05$, Mann-Whitney $U$ test) but no difference in the mean MD change during follow-up time ( $p>0.05$, Mann-Whitney U test) (Tab. I; Fig. 1 $\mathrm{G}-\mathrm{I})$. Interestingly, thinning of RNFL was significantly lower in patients without any reported elevations above the normative $21 \mathrm{~mm} \mathrm{Hg}$, if treatment with combination brimonidine + timolol therapy was applied, rather than if only timolol therapy was used.

\section{DISCUSSION}

In this report, we showed limited morphological, but not functional, neuroprotective effect over a five-year period of topical brimonidine + timolol compared with timolol, administered twice daily in primary open-angle glaucoma patients, which was shown in reduced thinning of RNFL, but not in the 


\begin{tabular}{|l|c|c|c|c|c|c|}
\hline \multicolumn{3}{|l}{$\begin{array}{l}\text { Table I. Mean } \pm \text { standard deviation (SD) values of intraocular pressure (IOP), retinal nerve fibre layer (RNFL), } \\
\text { and visual field mean deviation (MD) in subgroups }\end{array}$} \\
\hline Group & $\begin{array}{c}\text { IOP } \\
\text { [mm Hg] }\end{array}$ & $\begin{array}{c}\text { MD change } \\
{[\mathrm{dB}]}\end{array}$ & $\begin{array}{c}\text { Output RNFL } \\
\text { thickness } \\
{[\mu \mathrm{m}]}\end{array}$ & $\begin{array}{c}\text { Final RNFL } \\
\text { thickness } \\
{[\mu \mathrm{m}]}\end{array}$ & $\begin{array}{c}\text { RNFL loss } \\
{[\mu \mathrm{m}]}\end{array}$ & $\begin{array}{c}\text { Annual } \\
\text { RFNL loss } \\
{[\mu \mathrm{m} / \text { year] }}\end{array}$ \\
\hline BT (brimonidine + timolol) & $17.3 \pm 3.9$ & $2.5 \pm 0.5$ & $74.0 \pm 20.0$ & $66.1 \pm 14.1$ & $7.9 \pm 4.3$ & $1.7 \pm 1.5$ \\
\hline T (timolol) & $16.3 \pm 3.6$ & $1.3 \pm 0.7$ & $74.9 \pm 15.4$ & $65.7 \pm 12.9$ & $9.2 \pm 5.6$ & $1.8 \pm 1.5$ \\
\hline $\mathrm{BT}^{+}$(brimonidine + timolol) & $18.6 \pm 4.4$ & $2.8 \pm 1.4$ & $71.9 \pm 19.9$ & $62.3 \pm 10.7$ & $9.6 \pm 7.2$ & $1.9 \pm 1.4$ \\
\hline $\mathrm{T}^{+}$(timolol) & $18.3 \pm 5.1$ & $1.9 \pm 0.8$ & $71.3 \pm 17.6$ & $62.1 \pm 11.5$ & $9.2 \pm 7.9$ & $1.8 \pm 1.6$ \\
\hline $\mathrm{BT}^{-}$(brimonidine + timolol) & $15.1 \pm 1.5$ & $2.1 \pm 1.5$ & $77.8 \pm 20.5$ & $72.7 \pm 18.3$ & $5.1 \pm 1.8$ & $1.1 \pm 0.4$ \\
\hline $\mathrm{T}^{-}$(timolol) & $15.4 \pm 1.9$ & $1.0 \pm 0.9$ & $76.2 \pm 13.7$ & $67.0 \pm 12.8$ & $9.2 \pm 2.4$ & $1.8 \pm 0.9$ \\
\hline
\end{tabular}

$\mathrm{BT}^{+}$— brimonidine + timolol group with IOP spikes; $\mathrm{BT}$ - brimonidine + timolol group with no IOP spikes; $\mathrm{T}$ - timolol group with no IOP spikes; $\mathrm{T}^{+}$— timolol group with IOP spikes

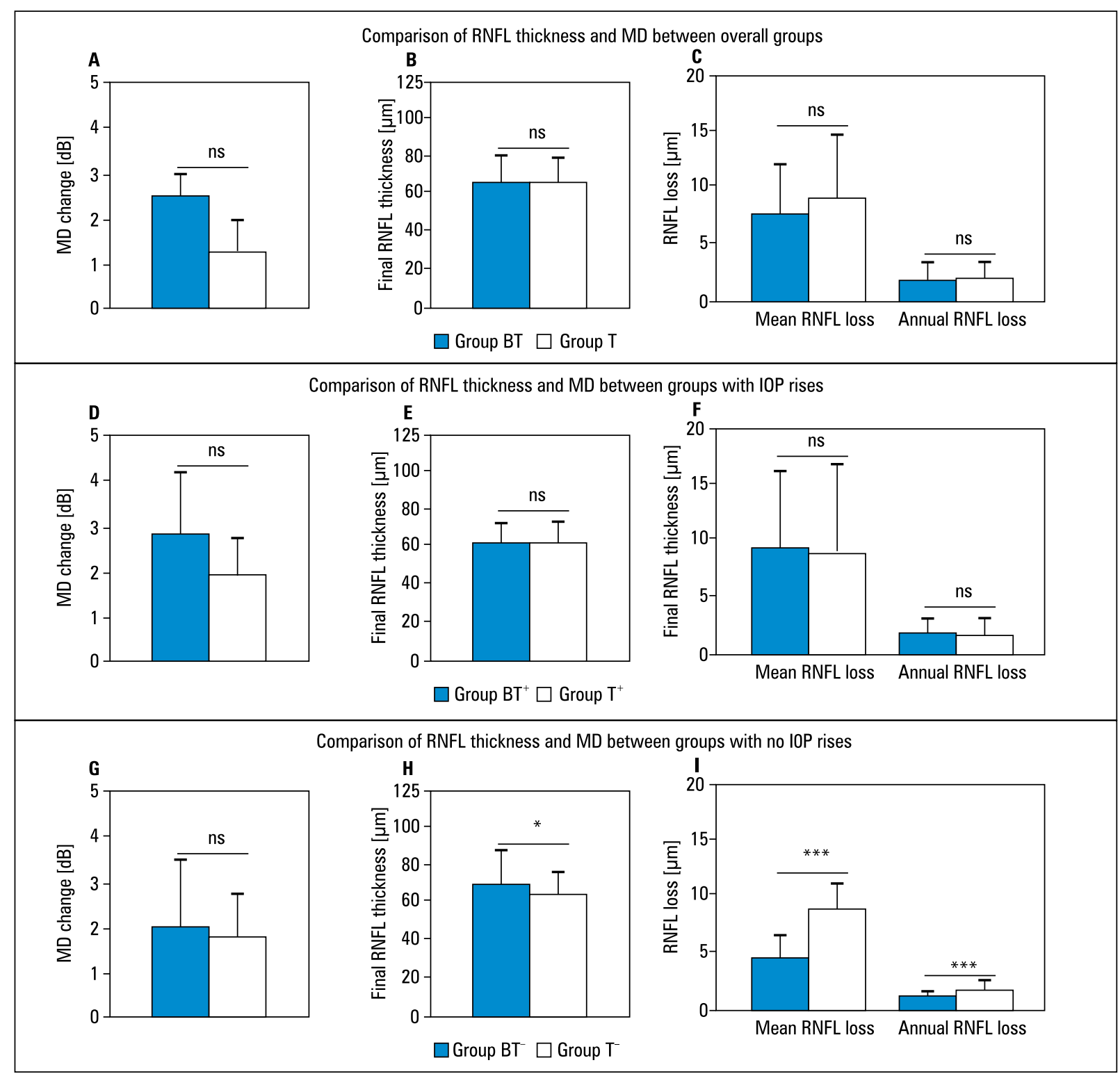

FIGURE 1. Comparison between study groups for retinal nerve fibre layer (RNFL) derived from ocular coherence tomography (OCT) and mead deviation (MD) derived from visual fields. A-C - comparison between group BT and T showed no statistical differences in MD changes, mean final RNFL thickness, and RNFL thickness loss rate. D-F - comparison between group $\mathrm{BT}^{+}$and $\mathrm{T}^{+}$showed no statistical differences in MD changes, mean final RNFL thickness, and RNFL thickness loss rate. G - comparison between group BT and group T showed no statistical differences in MD changes, but there was a significant difference in mean final RNFL thickness (H) and RFNL thickness loss rate (I) 
VF MD coefficient. Since no significant difference between IOP values in groups was observed, we estimate that the protective capacity of brimonidine is IOP-independent, although the exact molecular signalling mechanisms were not studied. In our study, patients with even single episodes of IOP rise above the normative $21 \mathrm{~mm} \mathrm{Hg}$ did not show additional benefit from the brimonidine + timolol treatment, when compared to the timolol group. Other studies showed no evidence for the neuroprotective activity of brimonidine in patients with high-pressure acute angle closure glaucoma or high-pressure open-angle glaucoma [10, 11]. Similarly, Tsai and Chang showed that patients with mean IOP $<21 \mathrm{~mm} \mathrm{Hg}$ treated with brimonidine appear to have lower RNFL loss compared to patients treated with timolol over a 12-month period [10]. In a low-tension glaucoma study, Krupin et al. reported that patients treated with topical brimonidine were less likely to have visual field progression than patients treated with topical timolol only [9]. Similar observations were done by Evans et al. using contrast sensitivity test as a tool to evaluate visual function [7]. Sebastiani et al. and Wessel et al. independently documented that the mean annual RNFL thickness loss in glaucoma patients varies between 1.1 and $2.1 \mu \mathrm{m} /$ year, while in healthy eyes the thickness loss is estimated to be $0.5-0.6 \mu \mathrm{m} /$ year $[12$, 13]. In our study, the mean RNFL loss varied between 1.7 and $1.8 \mu \mathrm{m} /$ year. It is known that IOP higher than $17 \mathrm{~mm} \mathrm{Hg}$ induces an additional $0.05 \mu \mathrm{m} /$ year RNFL loss for each increased $1 \mathrm{~mm} \mathrm{Hg}[14,15]$. Surprisingly, even single, short-lasting IOP peaks above $21 \mathrm{~mm} \mathrm{Hg}$ in our analysis, significantly decreased RNFL thickness, although mean IOP remained within the normal levels. Thus, it might be essential to observe daily fluctuations, especially in glaucoma patients who show disease progression. Retinal thickness analysis with the time domain OCT is commonly considered to be less reliable compared with the spectral domain OCT; however, numerous reports suggest that TD OCT is as reliable as SD OCT to measure RNFL thickness and glaucoma progression $[15,17]$.

\section{CONCLUSIONS}

Our results revealed that topical combination of brimonidine and timolol rather than timolol only may have an additional neuroprotective capacity in certain POAG patients who might depend on the IOP spikes, and even short-lasting single elevations of IOP may accelerate RNFL thinning.

\section{REFERENCES}

1. Quigley HA, Broman AT. The number of people with glaucoma worldwide in 2010 and 2020. Br J Ophthalmol. 2006; 90(3): 262-267, doi: 10.1136/bjo.2005.081224, indexed in Pubmed: 16488940.

2. Casson RJ. Pathogenesis of primary open-angle glaucoma. Clin Exp Ophthalmol. 2012; 40(9): 838-839, doi: 10.1111/ceo.12013, indexed in Pubmed: 23217143.

3. Musch DC, Gillespie BW, Niziol LM, et al. CIGTS Study Group. Intraocular pressure control and long-term visual field loss in the Collaborative Initial Glaucoma Treatment Study. Ophthalmology. 2011; 118(9): 1766-1773, doi: 10.1016/j.ophtha.2011.01.047, indexed in Pubmed: 21600658.

4. Danesh-Meyer HV. Neuroprotection in glaucoma: recent and future directions. Curr Opin Ophthalmol. 2011; 22(2): 78-86, doi: 10.1097/ ICU.0b013e32834372ec, indexed in Pubmed: 21252670.

5. Hernández M, Urcola JH, Vecino E. Retinal ganglion cell neuroprotection in a rat model of glaucoma following brimonidine, latanoprost or combined treatments. Exp Eye Res. 2008; 86(5): 798-806, doi: 10.1016/j. exer.2008.02.008, indexed in Pubmed: 18394603.

6. Saylor M, McLoon LK, Harrison AR, et al. Experimental and clinical evidence for brimonidine as an optic nerve and retinal neuroprotective agent: an evidence-based review. Arch Ophthalmol. 2009; 127(4): 402-406, doi: 10.1001/archophthalmol.2009.9, indexed in Pubmed: 19365015.

7. Evans DW, Hosking SL, Gherghel D, et al. Contrast sensitivity improves after brimonidine therapy in primary open angle glaucoma: a case for neuroprotection. Br J Ophthalmol. 2003; 87(12): 1463-1465, indexed in Pubmed: 14660453.

8. Cantor LB, Safyan E, Liu CC, et al. Brimonidine in the treatment of glaucoma and ocular hypertension. Ther Clin Risk Manag. 2006; 2(4): 337-346, indexed in Pubmed: 18360646.

9. Krupin T, Liebmann JM, Greenfield DS, et al. Low-Pressure Glaucoma Study Group. A randomized trial of brimonidine versus timolol in preserving visual function: results from the Low-Pressure Glaucoma Treatment Study. Am J Ophthalmol. 2011; 151(4): 671-681, doi: 10.1016/j. ajo.2010.09.026, indexed in Pubmed: 21257146.

10. Tsai JC, Chang HW. Comparison of the effects of brimonidine $0.2 \%$ and timolol $0.5 \%$ on retinal nerve fiber layer thickness in ocular hypertensive patients: a prospective, unmasked study. J Ocul Pharmacol Ther. 2005; 21(6): 475-482, doi: 10.1089/jop.2005.21.475, indexed in Pubmed: 16386089.

11. Aung T, Oen FTS, Wong HT, et al. Randomised controlled trial comparing the effect of brimonidine and timolol on visual field loss after acute primary angle closure. Br J Ophthalmol. 2004; 88(1): 88-94, indexed in Pubmed: 14693782.

12. Costagliola C, Parmeggiani F, Ciancaglini M, et al. Effects of acute topical administration of clonidine $0.125 \%$, apraclonidine $1.0 \%$ and brimonidine $0.2 \%$ on visual field parameters and ocular perfusion pressure in patients with primary open-angle glaucoma. Acta Ophthalmol Scand Suppl. 2002; 236(1): 29-30, indexed in Pubmed: 12390124.

13. Wessel JM, Horn FK, Tornow RP, et al. Longitudinal analysis of progression in glaucoma using spectral-domain optical coherence tomography. Invest Ophthalmol Vis Sci. 2013; 54(5): 3613-3620, doi: 10.1167/ iovs.12-9786, indexed in Pubmed: 23633657.

14. Grewal DS, Sehi M, Paauw JD, et al. Advanced Imaging in Glaucoma Study Group. Detection of progressive retinal nerve fiber layer thickness loss with optical coherence tomography using 4 criteria for functional progression. J Glaucoma. 2012; 21(4): 214-220, doi: 10.1097/IJG. Ob013e3182071cc7, indexed in Pubmed: 21654510.

15. Medeiros F, Alencar L, Zangwill $L$, et al. The Relationship between Intraocular Pressure and Progressive Retinal Nerve Fiber Layer Loss in Glaucoma. Ophthalmology. 2009; 116(6): 1125-1133.e3, doi: 10.1016/j.ophtha.2008.12.062.

16. Chang RT, Knight OJ, Feuer WJ, et al. Sensitivity and specificity of time-domain versus spectral-domain optical coherence tomography in diagnosing early to moderate glaucoma. Ophthalmology. 2009; 116(12): 2294-2299, doi: 10.1016/j.ophtha.2009.06.012, indexed in Pubmed: 19800694.

17. Takagishi M, Hirooka K, Baba T, et al. Comparison of retinal nerve fiber layer thickness measurements using time domain and spectral domain optical coherence tomography, and visual field sensitivity. J Glaucoma. 2011; 20(6): 383-387, doi: 10.1097/IJG.0b013e3181 efb371, indexed in Pubmed: 20717050. 